\title{
Time Course and Mechanism of Oxidative Stress and Tissue Damage in Rat Liver Subjected to In Vivo Ischemia-Reperfusion
}

Beatriz González-Flecha, Juan Carlos Cutrin, and Alberto Boveris

Division Fisicoquimica, Facultad de Farmacia y Bioquimica, Universidad de Buenos Aires, 1113 Buenos Aires, Argentina

\begin{abstract}
The time course of oxidative stress and tissue damage in zonal liver ischemia-reperfusion in rat liver in vivo was evaluated. After $180 \mathrm{~min}$ of ischemia, surface chemiluminescence decreased to zero, state 3 mitochondrial respiration decreased by $70-80 \%$, and xanthine oxidase activity increased by $26 \%$ without change in the water content and in the activities of superoxide dismutase, catalase, and glutathione peroxidase. After reperfusion, marked increases in oxyradical production and tissue damage were detected. Mitochondrial oxygen uptake in state 3 and respiratory control as well as the activities of superoxide dismutase, catalase, and glutathione peroxidase and the level of nonenzymatic antioxidants (evaluated by the hydroperoxide-initiated chemiluminescence) were decreased. The severity of the post-reperfusion changes correlated with the time of ischemia. Morphologically, hepatocytes appeared swollen with zonal cord disarrangement which ranged from mild to severe for the tissue reperfused after 60-180 min of ischemia. Neutrophil infiltration was observed after $180 \mathrm{~min}$ of ischemia and 30 min of reperfusion. Mitochondria appear as the major source of hydrogen peroxide in control and in reperfused liver, as indicated by the almost complete inhibition of hydrogen peroxide production exerted by the uncoupler carbonylcyanide $p$-(trifluoromethoxy) phenylhydrazone. Additionally, inhibition of mitochondrial electron transfer by antimycin in liver slices reproduced the inhibition of state 3 mitochondrial respiration and the increase in hydrogen peroxide steady-state concentration found in reperfused liver. Increased rates of oxyradical production by inhibited mitochondria appear as the initial cause of oxidative stress and liver damage during early reperfusion in rat liver. (J. Clin. Invest. 1993.91:456-464.) Key words: chemiluminescence $\bullet$ hydrogen peroxide $\bullet$ mitochondrial damage $\bullet$ reperfusion injury $\bullet$ xanthine oxidase
\end{abstract}

\section{Introduction}

Oxidative stress, defined as an increase in the physiologic intracellular steady-state concentrations of active oxygen species ( superoxide anion $\left[\mathrm{O}_{2}^{-}\right]$, hydrogen peroxide $\left[\mathrm{H}_{2} \mathrm{O}_{2}\right]$, hydroxyl radical $\left[\mathrm{HO}^{\circ}\right]$, peroxyl radicals $\left[\mathrm{ROO}^{\circ}\right]$, and singlet oxygen $\left.\left[{ }^{1} \mathrm{O}_{2}\right]\right)(1,2)$, has been related to reperfusion injury in heart $(3$,

Address reprint requests to Dr. Beatriz Gonzalez-Flecha, Division Fisicoquimica, Facultad de Farmacia y Bioquimica, Universidad de Buenos Aires, Junin 956, 1113 Buenos Aires, Argentina.

Received for publication 17 September 1991 and in revised form 14 August 1992.

J. Clin. Invest.

(C) The American Society for Clinical Investigation, Inc.

0021-9738/93/02/0456/09 \$2.00

Volume 91, February 1993, 456-464
4), kidney $(5,6)$, liver $(7,8)$, lung (9), and intestine (10,11). However, the molecular mechanisms by which oxidative stress is produced as well as the time course of the phenomenon are still unclear due to lack of studies measuring or evaluating the major sources of oxygen free radicals in the same experimental model.

Parks et al. (12,13) and Mc Cord (14) in 1981-1985 put forth the first hypothesis to explain reperfusion tissue injury; cytosolic xanthine oxidase, derived from dehydrogenase conversion during ischemia, was considered for many years as the main source of superoxide anion during reperfusion of ischemic tissues. This hypothesis was supported by the protective effects of xanthine oxidase inhibitors (i.e., allopurinol and oxopurinol). Several studies were performed to assess the quantitative and mechanistic aspects of the dehydrogenase to oxidase conversion during liver ischemia and reperfusion (15-18). However, these studies were performed in isolated and perfused liver and changes occurring during hypoxia were not correlated to tissue damage observed after reperfusion.

The mitochondrial hypothesis for tissue damage in ischemia and reperfusion presented here, proposes that during ischemia the lack of electron aceptor, molecular oxygen, and an inhibition of electron transfer by ischemia by-products and/or morphologic disarrangement lead to a high reduction of the components of the mitochondrial respiratory chain. Upon reoxygenation, a burst of superoxide anion production occurs owing to the increased autooxidation rate of the major intramitochondrial sources of superoxide anion, namely, ubisemiquinone $\left(\mathrm{UQH}^{\circ}\right)^{1}$ and $\mathrm{NADH}$-dehydrogenase flavin-semiquinone $\left(\mathrm{FMNH}^{\circ}\right)$. Both semiquinone concentrations are relatively increased because of steady inhibition of electron transfer. Intramitochondrial superoxide anion, unable to diffuse out of mitochondria, yields by the action of Mn-superoxide dismutase, intramitochondrial hydrogen peroxide that diffuses through mitochondrial membranes to the cytosol. The result of the primarily increased rate of intramitochondrial superoxide anion will be an increase in the whole cellular hydrogen peroxide steady-state concentration. Hydrogen peroxide will react with the hemes of both intramitochondrial cytochrome $c$ and cytosolic cytochrome $\mathrm{P}_{450}$, yielding either hydroxyl radical $\left(\mathrm{HO}^{\circ}\right)$ or perferrylhemoproteins $\left(\mathrm{Fe}^{\mathrm{IV}}=\mathrm{O}\right)(19)$ and providing highly reactive oxidizing species capable of initiating free radical chain reactions (Fig. 1).

This article reports evidence of the time course of liver reperfusion injury in terms of oxidative stress indicators (hydrogen peroxide steady-state concentration and spontaneous chemiluminescence) and markers of $(a)$ tissue (morphology and

1. Abbreviations used in this paper: ALT, alanine aminotransferase; AST, aspartate aminotransferase; FCCP, carbonylcyanide p-(trifluoromethoxy) phenylhydrazone; LDH, lactate dehydrogenase; $\mathrm{FMNH}^{\circ}$, $\mathrm{NADH}$ dehydrogenase flavin-semiquinone; UQ, ubiquinone; $\mathrm{UQH}^{\circ}$, ubisemiquinone. 


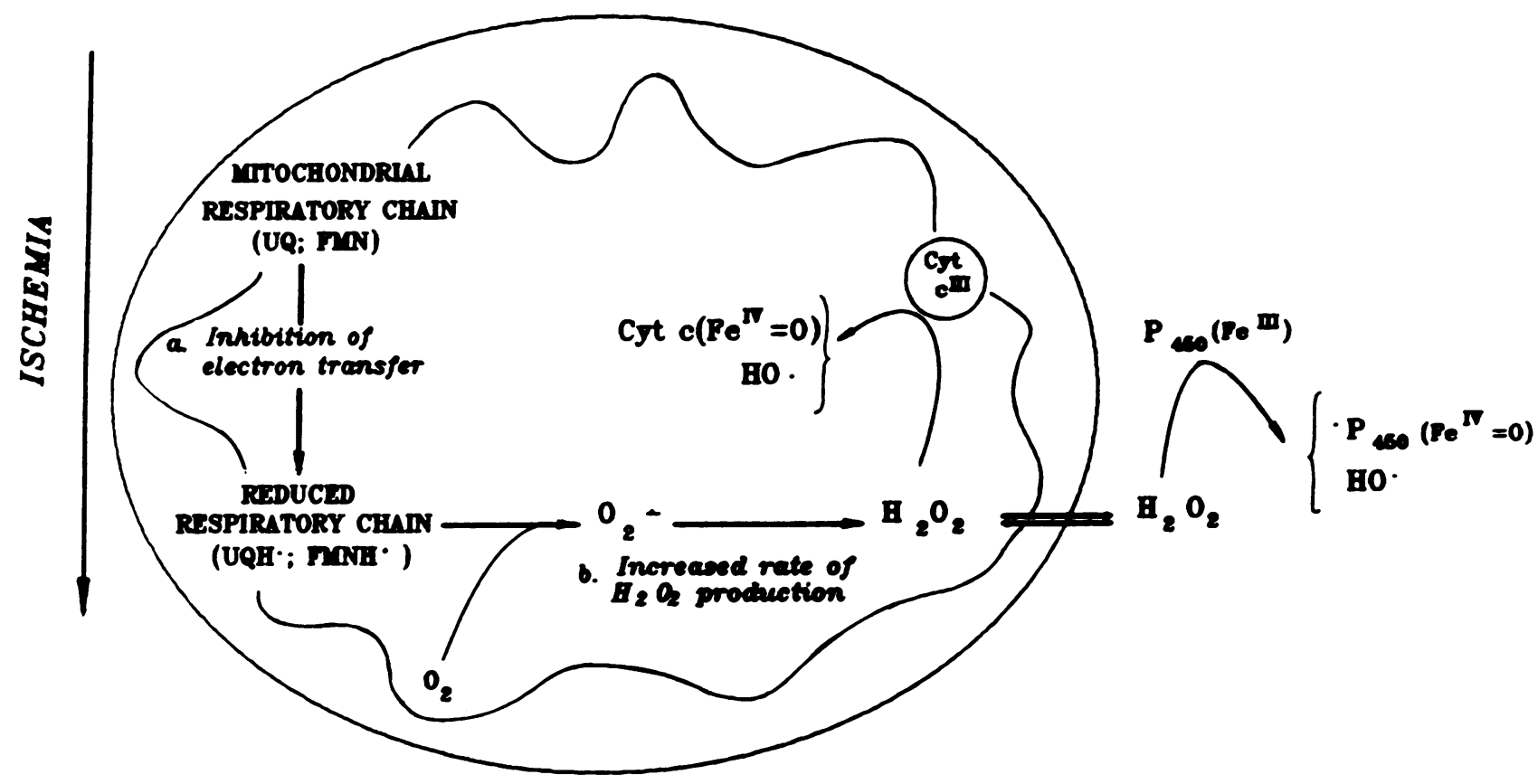

REPERFUSION

Figure 1. Scheme of the proposed mechanism for $\mathrm{O}_{2}^{-} / \mathrm{H}_{2} \mathrm{O}_{2}$ increase associated to ischemia-reperfusion in liver. Statements $a$ and $b$ represent mitochondrial changes during ischemia $(a)$ and reperfusion $(b)$. UQ and $\mathrm{UQH}^{\circ}$, oxidized and reduced forms of ubiquinone; FMN and FMNH', oxidized and reduced forms of NADH dehydrogenase flavoprotein; $\mathbf{P}_{450}$, cytochrome $\mathrm{P}_{450} ;$ Cyt c, cytochrome $c ; \mathrm{Fe}^{\mathrm{IV}}=\mathrm{O}$, perferryl hemoprotein.

water content), $(b)$ cell ( serum activities of lactate dehydrogenase $[\mathrm{LDH}]$, aspartate aminotransferase $[\mathrm{AST}]$, and alanine aminotransferase $[\mathrm{ALT}]$ ), and $(c)$ mitochondrial damage ( $\mathrm{mi}-$ tochondrial respiratory activities). The relative contributions of cytosolic and mitochondrial compartments as oxyradical sources in ischemia-reperfusion are also evaluated.

\section{Methods}

Experimental model. Male Wistar rats weighing $180-200 \mathrm{~g}$ fed a conventional laboratory diet and water ad libitum were used. Rats were fasted $24 \mathrm{~h}$ before surgery. Animals were anticoagulated with sodium heparine ( $400 \mathrm{IU} / \mathrm{kg}$ body wt) and anesthetized with sodium pentobarbital $(50 \mathrm{mg} / \mathrm{kg}$ body $\mathrm{wt}$ ), and the liver was exposed by transverse abdominal incision. The liver lobes were gently moved to expose the branches of the portal vein and hepatic artery to the right and left lobes. The right branches of the hepatic artery and portal vein were temporarily ligated as previously described by Jaeschke et al. (20) and Metzger et al. (21), rendering about one-third of the total hepatic mass ischemic. Left lobes were used as control tissue. The abdominal cavity was then closed and the rats were positioned under warming lamps to maintain constant body temperature. After 60,120 , or $180 \mathrm{~min}$ of warm ischemia, the abdomen was reopened and the ligature was removed to allow reperfusion in the ischemic lobes. The abdominal cavity was closed again and reopened after $30 \mathrm{~min}$ of reperfusion. During ischemia and after reperfusion blood and liver samples from the right lobes were taken to be processed.

Spontaneous liver chemiluminescence. Spontaneouschemiluminescence of the surface of the right upper lobe of the in situ liver was monitored using a photon counter (Johnson Research Foundation, University of Pennsylvania, Philadelphia, PA) with a model 9658 pho- tomultiplier (responsive in the range $300-900 \mathrm{~nm}$; Thorn EMI, Ruislip, Middlesex, England) as described (22). The emission was expressed as counts per second per unit of liver surface $\left(\mathrm{cps} / \mathrm{cm}^{2}\right)$.

Marker enzymes of liver damage. Serum samples taken before surgery and after reperfusion were processed for the determination of LDH, ALT, and AST activities using commercial laboratory kits. Values are given in units per liter of serum.

Water content. Liver samples $(\sim 1 \mathrm{~g})$ were weighed and then dried in a convection oven at $70^{\circ} \mathrm{C}$ for $48 \mathrm{~h}$. Water content was calculated as the difference between wet and dry weights and referred to the initial wet weight as percentage.

Morphologic studies. Small fragments of liver were resected at the end of experiments, fixed in $10 \%$ formaldehyde in $50 \mathrm{mM}$ phosphate buffer ( $\mathrm{pH} 7.0$ ), embedded in paraffin, sectioned, and stained with hematoxilin and eosin.

Oxygen uptake. Liver slices ( $0.1 \mathrm{~mm}$ thick) were placed in KrebsRinger solution containing $10 \mathrm{mM}$ glucose in the reaction chamber of an Clark-type oxygen electrode at $30^{\circ} \mathrm{C}$. The medium was air-equilibrated at $0.22 \mathrm{mM}$ oxygen (23). The initial rate of oxygen uptake was monitored during $10 \mathrm{~min}$.

Mitochondrial respiratory activities. Mitochondria were isolated from liver homogenized in $0.23 \mathrm{M}$ mannitol, $0.07 \mathrm{M}$ sucrose, $1 \mathrm{mM}$ EDTA, and $5 \mathrm{mM}$ Tris- $\mathrm{HCl}$ (pH 7.3) as described (24). Respiratory rates were measured with a Clark-type oxygen electrode in a reaction medium containing $0.25 \mathrm{M}$ sucrose, $20 \mathrm{mM} \mathrm{KCl}, 5 \mathrm{mM} \mathrm{MgCl} 2,1 \mathrm{mM}$ EDTA, $10 \mathrm{mM}$ Tris- $\mathrm{HCl}$, and $7 \mathrm{mM}$ phosphate $\left(\mathrm{pH} \mathrm{7.2)}\right.$ at $30^{\circ} \mathrm{C}$ using either $6 \mathrm{mM}$ malate and $6 \mathrm{mM}$ glutamate or $8 \mathrm{mM}$ succinate and 6 $\mathrm{mM}$ glutamate to measure state 4 respiration rates and the same substrates plus $0.5 \mathrm{mM}$ ADP to measure state 3 respiration rates. Respiratory control was determined as the ratio of oxygen uptake in state $3 /$ state 4 (23).

Xanthine dehydrogenase and oxidase activities. Liver samples were homogenized in $140 \mathrm{mM} \mathrm{KCl}, 1 \mathrm{mM}$ phenylmethylsulfonyl fluoride 
(to avoid the irreversible conversion from dehydrogenase to oxidase), $1 \mathrm{mM}$ dithiothreitol (to avoid the reversible conversion from dehydrogenase to oxidase) and $20 \mathrm{mM}$ Tris- $\mathrm{HCl}(\mathrm{pH} 7.6)$, and centrifuged at $15,000 \mathrm{~g}$ for $20 \mathrm{~min}$ at $0-4^{\circ} \mathrm{C}$. The post-peroxisomal supernatant was used for the determinations. Activities were measured in a Perkin Elmer Corp. (Norwalk, CT) model 356 spectrophotometer in the dualwavelength mode. Xanthine oxidase activity was measured by following uric acid appearance $\left(E_{293-320}=12.4 \mathrm{mM}^{-1} \mathrm{~cm}^{-1}\right)(24)$ in a reaction medium containing $0.1 \mathrm{M}$ Tris- $\mathrm{HCl}(\mathrm{pH} 8.6)$ and $50 \mu \mathrm{M}$ xanthine. Xanthine dehydrogenase activity was determined by following NADH appearance $\left(E_{340-375}=2.88 \mathrm{mM}^{-1} \mathrm{~cm}^{-1}\right)$ in the same reaction medium plus $0.1 \mathrm{mM} \mathrm{NAD}^{+}$. Measurements were carried out within the first hour after supernatant isolation. In preliminary experiments, these conditions were shown to preserve the enzyme from in vitro conversion during $6 \mathrm{~h}$ at $0-4^{\circ} \mathrm{C}$, or $12 \mathrm{~h}$ at $-20^{\circ} \mathrm{C}$.

Tissue homogenates. Samples to be processed for hydroperoxideinitiated chemiluminescence and for the determination of the activity of antioxidant enzymes $(0.5-1.0 \mathrm{~g}$ of wet weight $)$ were homogenized in $120 \mathrm{mM} \mathrm{KCl}, 30 \mathrm{mM}$ phosphate buffer $(\mathrm{pH} \mathrm{7.2})$ at $0-4^{\circ} \mathrm{C}$. The suspension was centrifuged at $600 \mathrm{~g}$ for $10 \mathrm{~min}$ at $0-4^{\circ} \mathrm{C}$ to remove nuclei and cell debris. The pellet was discarded and the supernatant was used as "homogenate" (25).

Hydroperoxide-initiated chemiluminescence. Tert-butyl hydroperoxide initiated-chemiluminescence was measured in a liquid scintillation counter in the out-of-coincidence mode (25). Homogenates were placed in low-potassium glass vials $(25 \mathrm{~mm} \times 50 \mathrm{~mm})$ at a protein concentration of $0.5-1.0 \mathrm{mg}$ of protein $/ \mathrm{ml}$ in a reaction medium consisting of $120 \mathrm{mM} \mathrm{KCl}, 30 \mathrm{mM}$ phosphate buffer ( $\mathrm{pH} \mathrm{7.5).} \mathrm{Measure-}$ ments were started by addition of $3 \mathrm{mM}$ tert-butyl hydroperoxide. The background level of emission of the empty vials was $2,500-3,000 \mathrm{cpm}$. Determinations were carried out at $30^{\circ} \mathrm{C}$ with occasional stirring. The results were expressed in $\mathrm{cps} / \mathrm{mg}$ protein.

Antioxidant enzymes. Superoxide dismutase activity was determined from the inhibition of the rate of autocatalytic adrenochrome formation in a reaction medium containing $1 \mathrm{mM}$ epinephrine and 50 $\mathrm{mM}$ glycine- $\mathrm{NaOH}$ ( $\mathrm{pH}$ 10.2) (26). The activity of the Mn-isoenzyme was assayed by adding $1 \mathrm{mM} \mathrm{KCN}$ to the reaction medium (27). Catalase activity was determined by measuring the decrease in absorption at $240 \mathrm{~nm}$ in a reaction medium containing $50 \mathrm{mM}$ phosphate buffer $(\mathrm{pH}$ 7.2) and $2 \mathrm{mM} \mathrm{H}_{2} \mathrm{O}_{2}$. The pseudo-first-order reaction constant $\left(k^{\prime}\right.$ $=k$. [Cat] ) of the decrease in $\mathrm{H}_{2} \mathrm{O}_{2}$ absorption was determined and the catalase content in $\mathrm{nmol} / \mathrm{g}$ liver was calculated using: $k=4.7 \times 10^{7}$ $\mathrm{M}^{-1} \mathrm{~s}^{-1}(28)$. Glutathione peroxidase activity was determined following NADPH oxidation at $340 \mathrm{~nm}$ in a reaction medium containing $0.17 \mathrm{mM} \mathrm{GSH}, 0.2 \mathrm{U} / \mathrm{ml}$ yeast glutathione reductase, $0.5 \mathrm{mM}$ tert-butyl hydroperoxide, and $50 \mathrm{mM}$ phosphate buffer ( $\mathrm{pH}$ 7.2) (29).

Intracellular steady-state concentration of hydrogen peroxide. Tissue slices $\sim 0.1 \mathrm{~mm}$ thick were incubated in $120 \mathrm{mM} \mathrm{NaCl}, 30 \mathrm{mM}$ phosphate buffer $(\mathrm{pH} 7.4)$ at $30^{\circ} \mathrm{C}$ and at a tissue/medium ratio of 1/20. Samples of the incubation medium were diluted 1:2.5 with 100 $\mathrm{mM}$ phosphate buffer ( $\mathrm{pH} 7.4$ ) containing $5 \mathrm{U}$ horseradish peroxidase and $40 \mu \mathrm{M} p$-hydroxyphenylacetic acid as hydrogen donor (30). Hydrogen peroxide concentration was calculated by subtracting the value of a sample treated with $0.1 \mu \mathrm{M}$ catalase from the value of an untreated sample. To test the effect of uncouplers and inhibitors in control and ischemia-reperfusion samples, liver slices were preincubated $10 \mathrm{~min}$ with $1.5 \mathrm{nmol}$ antimycin $/ \mathrm{mg}$ of mitochondrial protein, $0.2 \mu \mathrm{M}$ carbonylcyanide $p$-(trifluoromethoxy) phenylhydrazone (FCCP) or 1 $\mathrm{mM}$ allopurinol at $0-4^{\circ} \mathrm{C}$, washed twice with fresh phosphate-buffered saline, and assayed as described above.

Protein determination. Protein was measured by the method of Lowry et al. (31) using bovine serum albumin as standard.

Chemicals. tert-Butyl hydroperoxide was from Aldrich Chemical Co (Milwaukee, WI). Allopurinol, antymicin A, FCCP, dithiothreitol, epinephrine, glutathione reductase, glutathione, glycine, mannitol, $\mathrm{NAD}^{+}$, NADPH, phenylmethylsulfonyl fluoride, Tris, sucrose, and xanthine were from Sigma Chemical Co. (St. Louis, MO). Other reagents were of analytical grade. Kits for LDH, AST, and ALT were

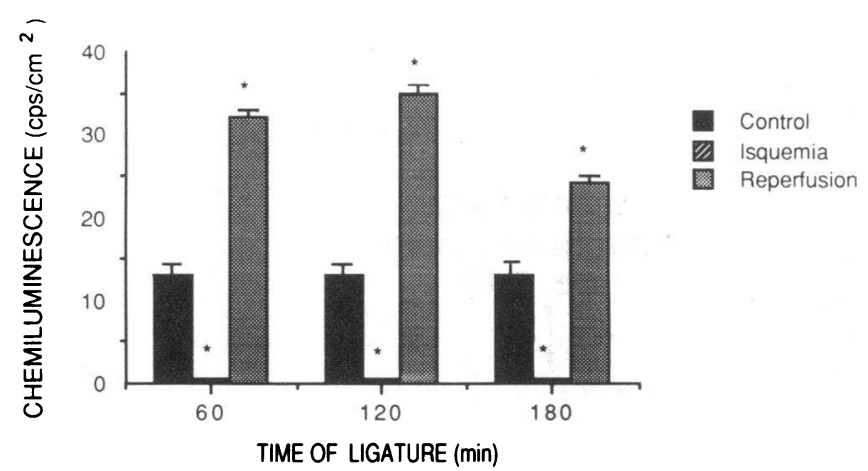

Figure 2. Spontaneous chemiluminescence of the liver in situ. Animals were anesthetized with pentobarbital and the liver surface was exposed by laparotomy. Bars represent mean values \pm SEM of six independent experiments. ${ }^{*} P<0.001$.

kindly provided by Boehringer Mannheim GmbH (Buenos Aires, Argentina).

Statistics. The numbers in tables and the symbols and bars in figures indicate mean values of six experiments \pm standard error of the mean (SEM). Data were analyzed statistically by factorial analysis of variance (ANOVA) followed by Dunnett's test for other comparisons (32).

\section{Results}

Spontaneous liver chemiluminescence. As previously described by Cadenas and Sies (33), singlet oxygen concentrations can be accurately approached by chemiluminescence. The surface chemiluminescence of normal liver in situ was $13 \pm 2 \mathrm{cps} / \mathrm{cm}^{2}$, constant over the experimental time and consistent with a steady state concentrations of singlet oxygen of about $10^{-14} \mathrm{M}$ $(9,33)$. The absence of light emission in ischemic liver agrees with the absence of oxygen free radical generation due to lack of molecular oxygen. Reperfusion of ischemic tissue produced marked increases in liver chemiluminescence $(110 \%, 140 \%$, and $60 \%$ for the reperfusion after 60,120 , and $180 \mathrm{~min}$ of ischemia, respectively) reflecting increases in singlet oxygen steady-state concentrations and indicating the occurrence of oxidative stress (Fig. 2).

Liver damage. Lactate dehydrogenase, aspartate aminotransferase, and alanine aminotransferase activities in serum samples obtained after reperfusion showed marked increases as compared to controls (Table I). Liver subjected to 60 or 120 min of ischemia did not show differences in water content

Table I. Enzymatic Serum Markers of Liver Damage and Water Content in the In Situ Rat Liver Subjected to Ischemia-Reperfusion

\begin{tabular}{ccccc}
\hline Ischemia/reperfusion & LDH & AST & ALT & $\begin{array}{c}\text { Water } \\
\text { content }\end{array}$ \\
\hline $\min$ & & U/liter & & $\%$ \\
$0 / 0$ & $195 \pm 15$ & $35 \pm 5$ & $42 \pm 2$ & $72 \pm 1$ \\
$60 / 30$ & $880 \pm 20^{*}$ & $120 \pm 7^{*}$ & $69 \pm 3$ & $76 \pm 1$ \\
$120 / 30$ & $1,350 \pm 30^{\ddagger}$ & $340 \pm 6^{\ddagger}$ & $91 \pm 7^{*}$ & $78 \pm 2^{*}$ \\
$180 / 30$ & $1,700 \pm 35^{\ddagger}$ & $370 \pm 5^{\ddagger}$ & $175 \pm 10^{\ddagger}$ & $80 \pm 1^{*}$
\end{tabular}

Values indicate mean value $\pm \mathrm{SEM}$ of six independent experiments. ${ }^{*} P<0.01 ;{ }^{\ddagger} P<0.001$. 

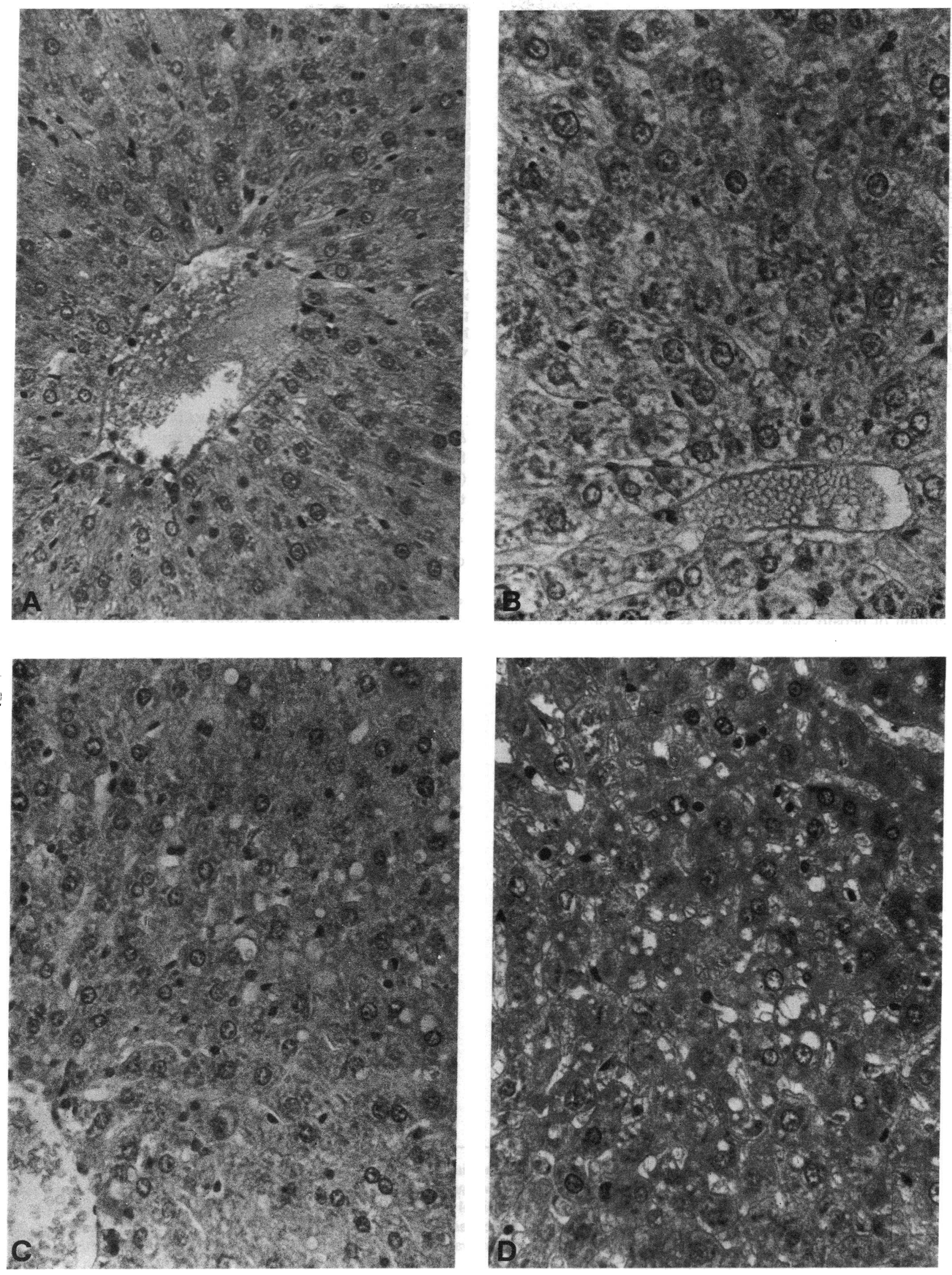


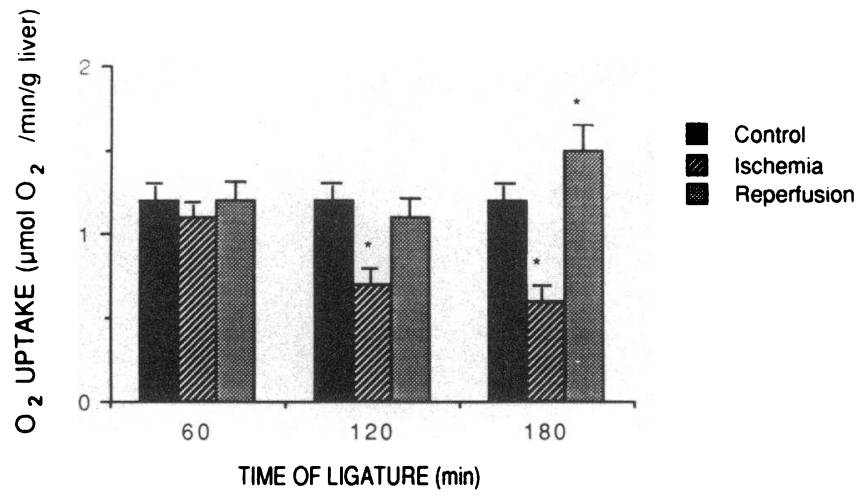

Figure 4. Oxygen consumption by tissue slices. Slides from control, ischemic, and reperfused tissue were incubated in air-saturated Krebs-Ringer solution added with $10 \mathrm{mM}$ glucose at $37^{\circ} \mathrm{C}$ with stirring. Initial $\mathrm{O}_{2}$ concentration was considered $0.22 \mathrm{mM}$ (21). Bars represent mean values \pm SEM of six independent experiments. ${ }^{*} P$ $<0.001$.

( $73 \pm 1 \%$ for both groups) while significant increases were measured after $180 \mathrm{~min}$ of ischemia $(75 \pm 1 \%)$ and for reperfusion samples ( Table I). Water content after reperfusion was linearly related to the time of ischemia $(r=0.98)$. Reperfusion injury was accompanied by marked morphologic changes. Whereas ischemia caused no discernible alterations in the histological appearance of hematoxylin and eosin stained liver (data not shown) ischemia followed by $30 \mathrm{~min}$ of reperfusion caused marked cellular injury (Fig. 3). In particular, vacuolar degeneration of hepatocytes was noted as well as cord disarrangement and portal edema which varied from slight to severe as ischemia duration increased. Liver subjected to $180 \mathrm{~min}$ of ischemia-30 min of reperfusion showed a marked infiltration by neutrophils as well as an increase in hepatocytes nuclear volume. Differences among zones were noted; acinar zones 2 and 3 were affected the most.

Oxygen consumption by tissue slices. The oxygen uptake of tissue slices obtained from ischemic livers was decreased with respect to control samples. The rate of oxygen uptake was inversely related to the time of ischemia indicating mitochondrial damage secondary to the lack of oxygen. Increased rates of oxygen uptake were measured after reperfusion (Fig. 4), indicating recovery of oxidative metabolism as well as an overuptake of oxygen due to oxyradical generation and lipid peroxidation; this later was well evident in the liver with $180 \mathrm{~min}$ of ischemia-30 min of reperfusion.

Hydroperoxide-initiated chemiluminescence. No change was observed in hydroperoxide-initiated chemiluminescence in short-time ischemic samples. Values for this ratio were significantly higher than control values after $180 \mathrm{~min}$ of ischemia and for ischemia-reperfusion (Fig. 5), indicating for these two latter situations the occurrence of oxidative stress or marked tissue damage (25) with consumption of endogenous nonenzymatic antioxidants such as tocopherols and retinoids (25).

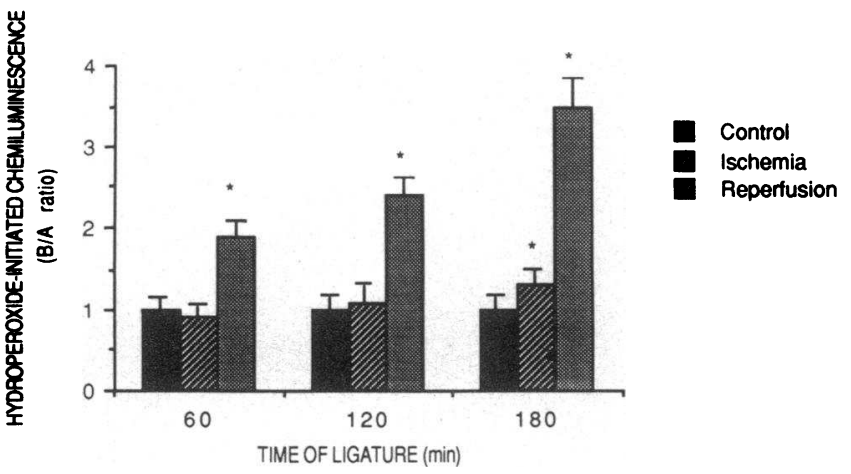

Figure 5. Post-reperfusion/control (B/A) ratio for the hydroperoxide-initiated chemiluminescence of liver homogenates. At each time point samples were taken homogenized and assayed to determine the hydroperoxide-initiated chemiluminescence. Bars represent mean values \pm SEM of six independent experiments. ${ }^{*} P<0.001$.

Correlation between the indicators of oxidative stress and liver damage. The reperfusion/control ratio (B/A) calculated for the values of hydroperoxide-initiated chemiluminescence (Fig. 5) linearly correlated with the same ratio calculated for the values of the markers of liver damage (Table I) (LDH, $r$ $=0.94$; AST, $r=0.93$; ALT, $r=0.87$ and water content $r$ $=0.98)$. Other oxidative stress indicators gave less significant correlations $(r<0.60)$.

Mitochondrial respiratory activities. No changes were observed in ischemia and ischemia-reperfusion samples in the mitochondrial rate of oxygen uptake in the controlled respiration (in the absence of ADP: state 4) but marked decreases were found in the rate of active respiration (with ADP: state 3) in both ischemia and ischemia-reperfusion (Table II). Respiratory control as an indicator of the coupling of oxidative phosphorylation showed marked changes for short ischemia times, that reflected the decreased state 3 respiration (Table II). Respiratory control values linearly related both to the time of ischemia $(r=-0.97)$ and to the level of markers of cell damage (LDH, $r=-0.996$; AST, $r=-0.97$; ALT, $r=-0.86$; and water content $(r=0.99)$ (Table I). Reperfusion further decreased state 3 respiration rates and respiratory control ratios (Table II).

Xanthine dehydrogenase and oxidase activities. An almost linear increase in xanthine oxidase activity with the time of ischemia was observed (Table III). The ratio dehydrogenase/ oxidase activities does not appear as a good indicator of enzyme conversion since significant changes in this relation did not correlate with significant changes in the oxidase activity (Table III). Increases in xanthine oxidase activity during ischemia gave good correlations with the increase in the markers of tissue damage during reperfusion (LDH, $r=0.95$; AST, $r$ $=0.92 ;$ ALT, $r=0.99$ and water content $r=0.95$ ) (Table I). The rates of superoxide and hydrogen peroxide production can be calculated from the measured activity of xanthine oxidase as

Figure 3. Morphologic appearance of the rat liver before and after ischemia-reperfusion. $(A)$ Control lobe: hepatic cords around terminal hepatic venule are made up of polygonal cells with granular cytoplasm. $(B)$ Liver subjected to 60 min of ischemia- 30 min of reperfusion. The perivenular hepatocytes appear mildly tumefacted and it is possible to observe minimal trabeculae disarrangement. $(C)$ Liver subjected to 120 min of ischemia-30 min of reperfusion. Moderate vacuolar degeneration is evident as well as the hepatic cord disarrangement. $(D)$ Liver subjected to 180 min of ischemia-30 min of reperfusion hepatic cord disarrangement and vacuolar degen $u$ ration are more marked. In some hepatocytes nuclei appear tumefacted or piknotic. ( $\times 75$ in $A, C$, and $D$ and $\times 100$ in $B)$. 
Table II. Respiratory Activities in Mitochondria Isolated from Rat Livers Subjected to Ischemia and Ischemia-Reperfusion

\begin{tabular}{|c|c|c|c|}
\hline \multirow[b]{2}{*}{ Ischemia/reperfusion } & \multicolumn{2}{|c|}{ Oxygen uptake } & \multirow{2}{*}{$\begin{array}{l}\text { Respiratory } \\
\text { control } \\
\text { ratio }\end{array}$} \\
\hline & State 4 & State 3 & \\
\hline
\end{tabular}

$6 \mathrm{mM}$ malate $+6 \mathrm{mM}$ glutamate

$\begin{array}{cccc}0 / 0 & 23 \pm 3 & 193 \pm 13 & 8.0 \pm 0.4 \\ 60 / 0 & 31 \pm 5 & 150 \pm 5 & 4.8 \pm 0.2 \\ 120 / 0 & 33 \pm 4 & 79 \pm 5^{*} & 2.4 \pm 0.1^{*} \\ 180 / 0 & 28 \pm 2 & 40 \pm 4^{\ddagger} & 1.5 \pm 0.2^{\ddagger} \\ 60 / 30 & 22 \pm 2 & 55 \pm 5^{*} & 2.5 \pm 0.2^{*} \\ 120 / 30 & 24 \pm 2 & 40 \pm 5^{\ddagger} & 1.7 \pm 0.2^{\ddagger} \\ 180 / 30 & 31 \pm 2 & 40 \pm 5^{\ddagger} & 1.3 \pm 0.2^{\ddagger}\end{array}$

$8 \mathrm{mM}$ succinate $+6 \mathrm{mM}$ glutamate

$\begin{array}{cccc}0 / 0 & 33 \pm 4 & 241 \pm 15 & 7.5 \pm 0.4 \\ 60 / 0 & 37 \pm 5 & 150 \pm 10 & 3.8 \pm 0.2 \\ 120 / 0 & 40 \pm 5 & 118 \pm 9^{*} & 2.9 \pm 0.1^{*} \\ 180 / 0 & 40 \pm 5 & 92 \pm 10^{\ddagger} & 1.6 \pm 0.1^{\ddagger} \\ 60 / 30 & 38 \pm 7 & 76 \pm 6^{\ddagger} & 2.0 \pm 0.2^{\ddagger} \\ 120 / 30 & 48 \pm 9 & 79 \pm 12^{\ddagger} & 1.6 \pm 0.2^{\ddagger} \\ 180 / 30 & 58 \pm 10 & 80 \pm 10^{\ddagger} & 1.5 \pm 0.2^{\ddagger}\end{array}$

Respiratory control ratio was calculated as the ratio between the rate of mitochondrial respiration with (state 3) and without (state 4) added ADP. Values represent the mean \pm SEM of six independent experiments. ${ }^{*} P<0.01,{ }^{\ddagger} P<0.001$.

described (34). The calculated rates are 0.08 and $0.15 \mu \mathrm{M} \mathrm{s}^{-1}$ for superoxide anion and 0.28 and $0.60 \mu \mathrm{M} \mathrm{s}^{-1}$ for hydrogen peroxide in control and $180 \mathrm{~min}$ of ischemia-30 min of reperfusion samples, respectively.

Antioxidant enzymes. The liver activity of superoxide dismutases, catalase, and glutathione peroxidase decreased by $\sim 50 \%$ in the organ reperfused after 120 and 180 min of ischemia (Table IV). It is worth noting the higher inactivation of Mn-superoxide dismutase located in the mitochondrial matrix as compared with cytosolic $\mathrm{Cu}-\mathrm{Zn}$-superoxide dismutase which is consistent with an intramitochondrial generation of the damaging species.

Table III. Activities of Xanthine Dehydrogenase (XD) and Xanthine Oxidase (XO), XD/XO Ratio, and XO Activity Percentage in Rat Liver Subjected to Ischemia

\begin{tabular}{rlccc}
\hline Ischemia & \multicolumn{1}{c}{ XD } & XO & XD/XO & XO \\
\hline min & \multicolumn{2}{c}{$m U / g$ liver } & & $\%$ \\
0 & $216 \pm 27$ & $20 \pm 2$ & $10.8 \pm 1.0$ & $8 \pm 1$ \\
60 & $216 \pm 20$ & $26 \pm 3$ & $8.3 \pm 0.7$ & $11 \pm 1$ \\
120 & $171 \pm 25$ & $33 \pm 3$ & $5.2 \pm 0.5$ & $16 \pm 1^{*}$ \\
180 & $124 \pm 7^{*}$ & $45 \pm 6^{*}$ & $2.8 \pm 0.5^{*}$ & $27 \pm 2^{*}$ \\
& & & & \\
\hline
\end{tabular}

Values indicate the mean \pm SEM of six independent experiments. The values of $\mathrm{mU} / \mathrm{g}$ liver correspond to $\mathrm{nmol} / \mathrm{min} / \mathrm{g}$ liver. Values can be converted into $\mu \mathrm{M} \cdot \mathrm{s}^{-1}$ by multiplying by 60 . ${ }^{*} P<0.01$.
Table IV. Superoxide Dismutases, Catalase, and Glutathione Peroxidase Activities in Rat Liver Subjected to Ischemia-Reperfusion

\begin{tabular}{ccccc}
\hline & \multicolumn{4}{c}{ Ischemia/reperfusion } \\
\cline { 2 - 5 } & $0 / 0$ & $60 / 30$ & $120 / 30$ & $180 / 30$ \\
\hline $\begin{array}{c}\text { Superoxide } \\
\text { dismutase } \\
(U / g \text { liver })\end{array}$ & $110 \pm 15$ & $80 \pm 10$ & $55 \pm 5^{\ddagger}$ & $52 \pm 4^{\ddagger}$ \\
$\begin{array}{c}\text { Mn-SOD } \\
\text { Cu-Zn SOD }\end{array}$ & $750 \pm 30$ & $600 \pm 35^{*}$ & $390 \pm 25^{\ddagger}$ & $330 \pm 20^{\ddagger}$ \\
$\begin{array}{c}\text { Catalase } \\
\text { (nmol/g liver) }\end{array}$ & $1.15 \pm 0.08$ & $0.90 \pm 0.07^{*}$ & $0.60 \pm 0.07^{\ddagger}$ & $0.52 \pm 0.05^{\ddagger}$ \\
$\begin{array}{c}\text { Glutathione } \\
\text { peroxidase } \\
\text { (mU/g liver) }\end{array}$ & $850 \pm 40$ & $750 \pm 30^{*}$ & $450 \pm 30^{\ddagger}$ & $370 \pm 20^{\ddagger}$ \\
\hline
\end{tabular}

Values indicate the mean $\pm \mathrm{SEM}$ of six independent experiments. ${ }^{*} P$ $<0.01 ;{ }^{\ddagger} P<0.001$.

Intracellular sources of $\mathrm{H}_{2} \mathrm{O}_{2}$. Based on the free diffusion of hydrogen peroxide through cell membranes, its intracellular steady-state concentration can be approached by measuring the hydrogen peroxide concentration in the incubation medium of tissue slices after reaching diffusional equilibrium (intracellular concentration equals to extracellular concentration ) $(9,35,36)$. Moreover, the whole-tissue rate of hydrogen peroxide production can be calculated using the steady-state assumption that the rate of hydrogen peroxide production equals to the rate of hydrogen peroxide utilization and considering utilization by catalase as follows:

$\mathrm{d}\left[\mathrm{H}_{2} \mathrm{O}_{2}\right] / \mathrm{d} t=-\mathrm{d}\left[\mathrm{H}_{2} \mathrm{O}_{2}\right] / \mathrm{d} t=k \cdot\left[\mathrm{H}_{2} \mathrm{O}_{2}\right] \cdot[$ cat $]$,

being $\left.k=4 \times 10^{7} \mathrm{M}^{-1} \mathrm{~s}^{-1}\right)(27),\left[\mathrm{H}_{2} \mathrm{O}_{2}\right]$ the measured concentration of hydrogen peroxide in the incubation medium (Table $\mathrm{V})$, and [Cat] the concentration of catalase in the tissue (Table IV).

The intracellular concentration of hydrogen peroxide was five times higher after $120 \mathrm{~min}$ of ischemia than in the control tissue. The calculated rate of hydrogen peroxide production after ischemia-reperfusion was 2.5 times higher than in control conditions (Table V). The effect of mitochondrial inhibitors such as the uncoupler FCCP and the inhibitor of the electron transfer antimycin were studied to assess the relative contribution of mitochondrial generation of hydrogen peroxide to intracellular hydrogen peroxide steady-state concentrations. The xanthine oxidase inhibitor allopurinol was also tested to evaluate the quantitative role of xanthine oxidase in this model. Likewise, the effect of an increase in cytochrome $\mathrm{P}_{450}$ content by phenobarbital treatment was studied.

Mitochondrial uncouplers such as FCCP are known to reduce the rate of mitochondrial hydrogen peroxide production to negligible levels (37). FCCP addition to liver slices decreased the hydrogen peroxide steady-state concentration and production rate to zero both in control and in ischemia-reperfusion samples indicating that mitochondria may account for most of hydrogen peroxide production in rat liver.

Blocking mitochondrial electron transfer by antimycin produces an increase in the leakage of electrons from the respiratory chain causing a three- to fivefold increase in hydrogen 
Table V. Intracellular Hydrogen Peroxide Concentration and Production Rate by Rat Liver Slices Subjected to $120 \mathrm{~min}$ of Ischemia and 30 min of Reperfusion

\begin{tabular}{|c|c|c|c|c|}
\hline \multirow[b]{2}{*}{ Treatment } & \multicolumn{2}{|c|}{$\left[\mathrm{H}_{2} \mathrm{O}_{2}\right]$} & \multicolumn{2}{|c|}{$\mathrm{d}\left[\mathrm{H}_{2} \mathrm{O}_{2}\right] / d t$} \\
\hline & Control & $\begin{array}{l}\text { Ischemia- } \\
\text { reperfusion } \\
120 / 30\end{array}$ & Control & $\begin{array}{c}\text { Ischemia- } \\
\text { reperfusion } \\
120 / 30\end{array}$ \\
\hline & \multicolumn{2}{|c|}{$\mu M$} & \multicolumn{2}{|c|}{$\mu M s^{-1}$} \\
\hline None & $0.09 \pm 0.01$ & $0.43 \pm 0.04$ & $4.1 \pm 0.1$ & $10.3 \pm 0.1$ \\
\hline FCCP & 0 & 0 & 0 & 0 \\
\hline Allopurinol & $0.12 \pm 0.02$ & $0.42 \pm 0.02$ & $5.5 \pm 0.1$ & $10.1 \pm 0.1$ \\
\hline Antimycin & $0.30 \pm 0.03$ & $0.64 \pm 0.05$ & $13.8 \pm 0.1$ & $15.4 \pm 0.1$ \\
\hline $\begin{array}{c}\text { Phenobarbita } \\
\text { treatment }\end{array}$ & $0.16 \pm 0.05$ & $0.46 \pm 0.07$ & $9.2 \pm 0.1$ & $11.0 \pm 0.1$ \\
\hline
\end{tabular}

Values indicate the mean of six independent experiments \pm SEM.

peroxide production $(37,38)$. A threefold increase in hydrogen peroxide generation was found in control liver after antimycin supplementation. Slices from livers subjected to ischemia-reperfusion showed a slight further increase both in the hydrogen peroxide steady-state concentration and in the rate of hydrogen peroxide production when treated with antimycin.

Inhibition of xanthine oxidase by allopurinol had no signifcant effect on the hydrogen peroxide concentration and production rate in control and in ischemia-reperfusion samples ( Table $\mathrm{V})$. The rate of hydrogen peroxide production by xanthine oxidase (see below) was $\sim 7 \%$ of the measured total rate of hydrogen peroxide production in control and reperfused liver.

Phenobarbital treatment. Phenobarbital-treated animals subjected to ischemia-reperfusion did not show significant changes respect to untreated animals in liver hydrogen peroxide concentration and production rate (Table VI). The increases in the spontaneous chemiluminescence of the in situ liver and in the serum activity of LDH in $120 \mathrm{~min}$ of ischemia30 min of reperfusion were significantly higher in phenobarbital-treated rats as compared with untreated animals.

\section{Discussion}

The results presented here aim to establish the relative role of mitochondria, endoplasmic reticulum, and xanthine oxidase as sources of oxygen free radicals during ischemia-reperfusion cycles in rat liver in vivo, on a time scale, and in a quantitative mode.

Table VI. Ratios of Oxidative Stress and Cell Damage Markers after 120 min of Ischemia 30 min of Reperfusion in the Liver of Control and Phenobarbital-treated Rats

\begin{tabular}{lcc}
\hline & \multicolumn{2}{c}{$\begin{array}{c}\text { Ratio of ischemia-reperfusion values } \\
\text { to control values }\end{array}$} \\
\cline { 2 - 3 } & $\begin{array}{c}\text { Untreated } \\
\text { rats }\end{array}$ & $\begin{array}{c}\text { Phenobarbital-treated } \\
\text { rats }\end{array}$ \\
\hline$\left[\mathrm{H}_{2} \mathrm{O}_{2}\right]$ & $4 \pm 1$ & $3 \pm 1$ \\
Spontaneous chemiluminescence & $2.4 \pm 0.2$ & $3.0 \pm 0.2^{*}$ \\
LDH activity & $7 \pm 1$ & $18 \pm 2^{\ddagger}$ \\
\hline
\end{tabular}

${ }^{*} P<0.01 ;{ }^{\ddagger} P<0.001$.
During the ischemic period, the marked decrease observed in the steady-state concentration of singlet oxygen is consistent with a low oxygen supply and a $\mathrm{PO}_{2}$ low enough to keep the $\mathrm{O}_{2}$-dependent chain reaction of lipid peroxidation occurring at undetectable rates. The cytosolic space seemed well preserved in that no changes were found in the cytosolic and peroxisomal antioxidant enzymes ( superoxide dismutase, catalase, and glutathione peroxidase, in the nonenzymatic antioxidants determined by hydroperoxide-initiated chemiluminescence) and in water content. The respiratory capability of the tissue, evaluated by the oxygen uptake of liver slices and isolated mitochondria was found markedly decreased. Thus, there is a limitation in both oxidative phosphorylation for energy supply and in secondary oxidative processes during ischemia that occurs without apparent cell damage. These mitochondrial changes have been described and depend on intracellular calcium movement due to changes in cell energy charge (39).

Upon reperfusion, the resupply of oxygenated blood into the tissue allows restitution of oxidative metabolism associated to the development of oxidative stress which is basically assessed by the increase in singlet oxygen and hydrogen peroxide steady-state concentrations. The severity of oxidative stress and cell damage depends on the time of ischemia. In fact, the observed changes can be graded as slight, marked and more marked for 60,120 , and $180 \mathrm{~min}$ of ischemia. For example, after $60 \mathrm{~min}$ of ischemia, reperfusion increases the steady-state concentration of singlet oxygen and decreases both the concentration of chain-breaker antioxidants and antioxidant enzyme with a slight decrease in the oxygen uptake of tissue slices and isolated mitochondria. This situation was associated with slight increases in the marker enzymes of liver damage and water content and slight morphologic damage. After 120 or $180 \mathrm{~min}$ of ischemia, reperfusion produced a more severe oxidative stress situation with more marked increases in surface chemiluminescence and hydrogen peroxide concentration. Decreases in the activities of superoxide dismutase, catalase, and glutathione peroxidase and in nonenzymatic antioxidants and more marked increases both in the leakage of LDH, AST, and ALT and in water content were observed. Oxygen consumption by tissue slices was brought back to near normal values with an slight overshoot. In both situations mitochondrial state 3 respiration showed additional decreases during reperfusion reaching minimal values after $180 \mathrm{~min}$ of ischemia and $30 \mathrm{~min}$ of reperfusion.

It appears that short periods ( $60 \mathrm{~min}$ ) of warm ischemia results in reversible cell injury in which liver oxygen consumption returns to control levels when oxygen is resupplied after ischemia. Reperfusion after more prolonged periods of ischemia (120-180 $\mathrm{min}$ ) results in irreversible cell damage as detected by the higher than twofold increases in the hydrogen peroxide and singlet oxygen steady-state concentrations, the $50 \%$ inactivation of the antioxidant enzymes and by the lack of regulation in oxidative metabolism. These observations agree with a previous report on rat liver subjected to ischemia-reperfusion indicating a cellular end point for hepatocytes after $\sim 90$ min of ischemia (40).

Liver ischemia-reperfusion in the experimental condition reported here produced: $(a)$ inhibition of the mitochondrial electron transfer with decreased rates of state 3 respiration, $(b)$ in vivo conversion of xanthine dehydrogenase to the oxidase form, $(c)$ inactivation of antioxidant enzymes, and $(d)$ neutrophil infiltration. All these events may account for increases in 
the superoxide anion and hydrogen peroxide steady-state concentrations in liver cells. Among these, only inhibition of electron transfer and xanthine oxidase activity correlated with reperfusion cell damage as evaluated by the marker enzymes and water content. However, as observed by Brass et al. (15), Engerson et al. (16), and McKelvey et al. (17), xanthine dehydrogenase conversion proceeds slowly and it appears to be a consequence of cellular injury rather than the initial cause.

A kinetic analysis indicates that mitochondria were the first oxyradical source to undergo marked changes, starting after reperfusion following $60 \mathrm{~min}$ of ischemia and leading to increased rates of superoxide anion and hydrogen peroxide production. The inactivation of antioxidant enzymes, the xanthine dehydrogenase to oxidase conversion, and neutrophil infiltration developed gradually according to the previous time of ischemia and may be considered as amplifying events.

A quantitative analysis of the relevance of xanthine oxidase and inhibited mitochondria as oxyradical sources in the reperfused liver can be made by comparing the rates of superoxide anion and hydrogen peroxide production. Increases in superoxide anion and hydrogen peroxide production by xanthine oxidase were shown to be negligible respect to the total production of oxygen free radicals and do not correlate with the decrease in state 3 mitochondrial respiration developed at shortterm ischemia. A primary role for mitochondria is strongly suggested both by the absence of hydrogen peroxide production in the presence of mitochondrial uncouplers and by the reproduction of the increase in hydrogen peroxide concentration and production rate by reproducing in vitro the inhibition of the state 3 mitochondrial respiration.

Mitochondria are one of the main sources of oxygen free radicals in the liver under physiological conditions $(24,28,37$, 38 ) and probably the most important source in other mammalian organs. In addition to the characterization of $\mathrm{UQH}^{\circ}(41)$ and $\mathrm{FMNH}^{\circ}(42)$ as the components of the mitochondrial respiratory chain responsible for the intramitochondrial superoxide anion and hydrogen peroxide production in control conditions, an increase in the intramitochondrial superoxide anion and hydrogen peroxide production up to maximal values has been described when mitochondrial inhibitors of the electron transport were used $(37,38)$. Addition of antimycin produces maximal reduction of the components of the respiratory chain that are located on the substrate side of antimycin-sensitive site (i.e., cytochrome $b$, ubiquinone, nonheme iron, and flavoprotein) with a decrease in the rate of mitochondrial respiration in state 3 . Interestingly enough, the same changes were observed in ischemic mitochondria in this study as well as in previous reports in isolated rat liver $(18,42)$ and heart $(43)$.

Inactivation of antioxidant enzymes after reperfusion following long-term ischemia is unlikely to be the main event in reperfusion injury but may significantly amplify the increase in hydrogen peroxide steady-state concentrations by decreasing the rate of oxyradical utilization. In example, hydrogen peroxide steady-state concentration in the liver after $120 \mathrm{~min}$ of ischemia-30 min of reperfusion was five times higher than the control value. A 2.5 -fold increase was due to an increased rate of hydrogen peroxide production and the additional twofold increase was due to catalase inactivation.

Finally, the absence of significant changes in hydrogen peroxide steady state concentration after ischemia-reperfusion in phenobarbital-treated rats indicate cytochrome $\mathbf{P}_{450}$ is not significant in hydrogen peroxide generation during reperfusion.
The marked increases in spontaneous chemiluminescence and LDH serum activity indicate that the propagation steps of the hydrogen peroxide-initiated chain reaction clearly involve cytochrome $\mathbf{P}_{450}$ and lead to cell damage.

In summary, the results presented here support in quantitative and kynetic terms the mitochondrial hypothesis for oxyradical damage in liver reperfusion. Oxidative inactivation of antioxidant enzymes appears to be an important amplifying epiphenomenon after long-term ischemia, while xanthine oxidase activity and neutrophil infiltration appeared delayed and do not seem clearly related to cell or tissue damage. Cytochrome $\mathbf{P}_{450}$ appears as the cytosolic component that links the primarily increased mitochondrial hydrogen peroxide steady-state concentration and the related cell damage.

\section{Acknowledgments}

We would like to thank Dr. Enrique Cadenas for helpful discussion and Drs. Jorge D. Cortese, Iasha Sznajder, and David Rustchman for their critical reading of the manuscript.

This study was supported by grants from the National Research Council for Scientific and Technical Research of Argentina (CONICET), the University of Buenos Aires, and Antorchas Foundation. Dr. Gonzalez-Flecha is a Research Fellow of the University of Buenos Aires. Drs. Cutrin and Boveris are, respectively, Research Fellow and Established Investigator of CONICET.

\section{References}

1. Sies, H. 1985. Oxidative stress: Introductory remarks. In Oxidative Stress. H. Sies, editor. Academic Press, Inc., San Diego. 1-7.

2. Giulivi, C., J. F. Turrens, and A. Boveris. 1988. Chemiluminescence enhancement by trypanocidal drugs and by inhibitors of antioxidant enzymes in Trypanosoma cruzi. Mol. Biochem. Pharmacol. 30:243-252.

3. Ferreira, R., M. Burgos, S. Llesuy, J. Milei, B. Gonzalez Flecha, and A. Boveris. 1989. Reduction of reperfusion injury with mannitol cardioplegia. Ann. Thorac. Surg. 48:77-84.

4. Ferreira, R., J. Milei, S. Llesuy, B. Gonzalez Flecha, H. Hourquebie, L. Molteni, C de Palma, A. Paganini, L. Scervino, and A. Boveris. 1991. Antioxidant action of vitamins $A$ and $E$ in patients submitted to coronary artery bypass surgery. Vasc. Surg. 25:191-195.

5. Joannidis, M., B. Gunther, and W. Pfaller. 1989. Lipid-peroxidation an initial event in experimental acute renal failure. Ren. Physiol. Biochem. 12:4755.

6. Takenaka, M., Y. Tatsukawa, and K. Dohi. 1981. Protective effects of tocopherol and coenzyme $Q_{10}$ on warm ischemic damage of the rat kidney. Transplantation. 32:137-141.

7. Marotto, M. E., R. G. Thurman, and J. J. Lemasters. 1989. Early midzonal cell death during low-flow hypoxia in the isolated, perfused rat liver: protection by allopurinol. Hepatology. 8:585-590.

8. Jaeschke, H. 1990. Glutathione disulfide as index of oxidant stress in rat liver during hypoxia. Am. J. Physiol. 21:G 499-505.

9. Fisher, A. B., C. Dodia, Z. Tan, I. Ayene, and R. Eckenhof. 1991. Oxygendependent lipid peroxidation during lung ischemia. J. Clin. Invest. 88:674-679.

10. Roldan, E., C. Pinus, J. Turrens, and A. Boveris. 1989. Chemiluminescence of the ischaemic and reperfused intestine in vivo. Gut. 30:184-187.

11. Parks, D. A., T. A. Williams, and J. S. Beckman. 1988. Conversion of xanthine dehydrogenase to oxidase in ischemic rat intestine: a reevaluation. $\mathrm{Am}$. J. Physiol. 17:G768-774.

12. Parks, D. A., G. B. Bulkley, D. N. Granger, S. R. Hamilton, and J. M. Mc Cord. 1982. Ischemic injury in the cat small intestine: role of superoxide radicals. Gastroenterology. 82:9-15.

13. Parks, D. A., G. B. Bulkley, and D. N. Granger. 1983. Role of oxygen-derived free radicals in digestive tract diseases. Surgery. 94:415-422.

14. Mc Cord, J. M. 1985. Oxygen derived free radicals in postischemic tissue injury. N. Engl. J. Med. 312:159-163.

15. Brass, C. A., J. Narciso, and J. L. Gollan. 1991. Enhanced activity of the free radical producing enzyme xanthine oxidase in hypoxic rat liver. J. Clin. Invest. 87:424-431.

16. Engerson, T. D., T. G. McKelvey, D. B. Rhyne, E. B. Boggio, S. J. Snyder, and $H$. P. Jones. 1987. Conversion of xanthine dehydrogenase to oxidase in ischemic rat tissues. J. Clin. Invest. 79:1564-1570. 
17. McKelvey, T. G., M. E. Hollwarth, D. N. Granger, T. D. Engerson, U. Landler, and H. P. Jones. 1988. Mechanisms of conversion of xanthine dehydrogenase to xanthine oxidase in ischemic rat liver and kidney. Am. J. Physiol. 254:G753-760.

18. Jaeschke, H., and J. R. Mitchell. 1989. Mitochondria and xanthine oxidase both generate oxygen species in isolated perfused rat liver after hypoxic injury. Biochem. Biophys. Res. Commun. 160:140-147.

19. Cadenas, E. 1989. Biochemistry of oxygen toxicity. Annu. Rev. Biochem. 58:79-110.

20. Jaeschke, H., A. Farhood, and C. W. Smith. 1990. Neutrophils contribute to ischemia/reperfusion injury in rat liver in vivo. FASEB (Fed. Am. Soc. Exp. Biol.) J. 4:3355-3359.

21. Metzger, J., S. P. Dore, and B. H. Lauterburg. 1988. Oxidant stress during reperfusion of ischemic liver: no evidence for a role of xanthine oxidase. Hepatology. 8:580-584.

22. Boveris, A., E. Cadenas, R. Reiter, M. Filipowski, Y. Nakase, and B. Chance. 1979. Organ chemiluminescence: a noninvasive assay for oxidative radical reactions. Proc. Natl. Acad. Sci. USA. 77:347-351.

23. Estabrook, R. W. 1967. Mitochondrial respiratory control and the polarographic measurements of ADP:O ratios. Methods Enzymol. 10:41-47.

24. Boveris, A., N. Oshino, and B. Chance. 1972. The cellular production of hydrogen peroxide. Biochem. J. 128:617-630.

25. Gonzalez Flecha, B., S. Llesuy, and A. Boveris. 1991. Hydroperoxide-initiated chemiluminescence: an assay for oxidative stress in biopsies of liver, heart and muscle. Free Radical Biol. Med. 10:93-100.

26. Fraga, C., R. F. Arias, S. Llesuy, O. Koch, and A. Boveris. 1987. Effect of vitamin E- and selenium-deficiency on rat liver chemiluminescence. Biochem. $J$. 242:383-386.

27. Beauchamp, C. O., and I. Fridovich. 1973. Isoenzymes of superoxide dismutase from wheat germ. Biochim. Biophys. Acta. 317:50-64.

28. Chance, B., H. Sies, and A. Boveris. 1979. Hydroperoxide metabolism in mammalian tissues. Physiol. Rev. 59:527-605.

29. Flohe, L., and W. A. Gunzler. 1984. Assays of glutathione peroxidase. Methods Enzymol. 105:114-121.

30. Guilbault, G. G., P. J. Brignac, and M. Juneau. 1968. New substrates for the fluorometric determination of oxidative enzymes. Anal. Chem. 40:12561263.

31. Lowry, O. H., A. L. Rosebrough, A. L. Farr, and R. Randall. 1951. Protein measurement with the Folin phenol reagent. J. Biol. Chem. 193:265-275.

32. Winer, B. J. 1971. Statistical Principles in Experimental Design. Mc Graw Hill, Inc., New York.

33. Cadenas, E., and H. Sies. 1984. Low-level chemiluminescence as an indicator of singlet molecular oxygen in biological systems. Methods Enzymol. 105:2211-230.

34. Fridovich, I. 1970. Quantitative aspects of the production of superoxide anion radical by milk xanthine oxidase. J. Biol. Chem. 245:4053-4057.

35. Puntarulo, S., R. Sanchez, and A. Boveris. 1988. Hydrogen peroxide metabolism in soybean embryonic axes at the onset of germination. Plant Physiol. 86:626-630.

36. Bustamante, J., L. Guerra, L. Bredeston, J. Mordoh, and A. Boveris. 1991 Melanin content and hydroperoxide metabolism in human melanoma cells. Exp. Cell Res. 196:172-176.

37. Boveris, A., and B. Chance. 1973. The mitochondrial production of hydrogen peroxide. Biochem. J. 134:707-716.

38. Boveris, A., and E. Cadenas. 1982. Production of superoxide radicals and hydrogen peroxide in mitochondria. In Superoxide Dismutase. Volume II. L. W. Oberley, editor. CRC Press, Boca Raton, FL. 15-30.

39. Castillo-Olivares, J. L., M. Gosalvez, D. Azpeitia, E. Garcia Romero, M Blanco, and D. Figuera. 1972. Mitochondrial respiration and oxidative phosphorylation during hepatic preservation. J. Surg. Res. 2:85-89.

40. Chien, K. R., J. Abrams, R. G. Pfau, and J. L. Farber. 1977. Prevention by chlorpromazine of ischemic liver cell death. Am. J. Pathol. 88:539-558.

41. Boveris, A., and E. Cadenas. 1975. Mitochondrial production of superoxide anion and its relationship to the antimycin insensitive respiration. FEBS (Fed. Eur. Biochem. Soc.) Lett. 54:311-314.

42. Turrens, J., and A. Boveris. 1980. Generation of superoxide anion by the NADH dehydrogenase for bovine heart mitochondria. Biochem. J. 191:421-427.

43. Turrens, J. F., M. Beconi, J. Barilla, U. Chavez, and J. M. McCord. 1991. Mitochondrial generation of oxygen radicals during reoxygenation of ischemic tissues. Free Radical Res. Commun. 12-13:681-689. 